\title{
Photocatalytic behavior of silver vanadates: Microemulsion synthesis and post-reaction characterization
}

\author{
Carolina Belver $^{\mathrm{a}, *}$, Cristina Adán ${ }^{\mathrm{b}, 1}$, Sergio García-Rodríguez ${ }^{\mathrm{b}}$, Marcos Fernández-García b \\ a Sección Ingeniería Química, Universidad Autónoma de Madrid, Campus Cantoblanco, E-28049 Madrid, Spain \\ ${ }^{\mathrm{b}}$ Instituto de Catálisis y Petroleoquímica, CSIC, Campus Cantoblanco, E-28049 Madrid, Spain
}

\section{H I G H L I G H T S}

- Silver vanadates were synthesized by microemulsion methodology not exceeding $110^{\circ} \mathrm{C}$.

- Silver metallic nanoparticles decorated the surface of the silver vanadates.

- The photocatalytic properties were studied upon visible light.

- The stability of catalysts was evaluated after reaction.

- We report a synergistic effect between $\mathrm{Ag}^{0}$ particles and silver vanadates.

\section{A R T I C L E I N F O}

\section{Article history:}

Available online 5 December 2012

\section{Keywords:}

Silver vanadates

Visible-light-driven photocatalysts

Used-catalysts characterization

Dye photodegradation

\begin{abstract}
A B S T R A C T
Silver vanadates with light absorption properties in the visible region were successfully prepared by a low temperature pathway (not exceeding $110^{\circ} \mathrm{C}$ ) using an optimized microemulsion methodology. The resulting materials were evaluated as photocatalysts in Rhodamine B photodegradation and characterized before and after reaction. The silver vanadates displayed silver metallic nanoparticles decorating the surface. The as-prepared $\mathrm{Ag}_{3} \mathrm{VO}_{4}$ catalyst was the most active. Nevertheless, this silver vanadate suffered important changes during reaction. The initial structure evolves yielding a silver pyrovanadate, $\mathrm{Ag}_{4-}$ $\mathrm{V}_{2} \mathrm{O}_{7}$, with a concomitant increase of the number and size of the silver metallic nanoparticles. The synergy between these $\mathrm{Ag}^{0}$ particles and the photoactivity of the $\mathrm{Ag}_{4} \mathrm{~V}_{2} \mathrm{O}_{7}$ phase seems responsible of the high photoactivity of this material.
\end{abstract}

(ㄷ) 2012 Elsevier B.V. All rights reserved.

\section{Introduction}

Photocatalysis appears as a promising technology in Advanced Oxidation Processes (AOPs), offering a simple way of using solar light to induce chemical transformations. Pollution control is by far the most studied application of photocatalysis. The photocatalyst further used for this purpose has been titanium dioxide $\left(\mathrm{TiO}_{2}\right)$, for its excellent properties: high oxidative power, photostability and low cost. Unfortunately, $\mathrm{TiO}_{2}$ efficiency using sunlight is limited by its band gap value $(3.2 \mathrm{eV})$, undergoing photoinduction with ultraviolet (UV) radiation. Thus, its potential as a sustainable technology cannot be entirely fulfilled, limiting its industrial applications. However, in the last years, many researches are looking for other semiconductors susceptible to undergo photoinduction in the visible region, such as other oxides $\left(\mathrm{Fe}_{2} \mathrm{O}_{3}, \mathrm{SnO}, \mathrm{WO}_{3}\right)$,

\footnotetext{
* Corresponding author.

E-mail address: carolina.belver@uam.es (C. Belver).

1 Present address: Ingeniería Química y Medioambiental, Universidad Rey Juan Carlos, 28933 Madrid, Spain.
}

mixed oxides, metalates, nitrides and chalcogenides, or even cation interchanged zeolites and pillared clays [1-3]. The design of visible-driven photocatalysts involves the band gap reduction of the well-known semiconductors that are active using UV light. Therefore, an important approach to this purpose is the creation of new energy levels between the bands of the semiconductor using dopant species and thus increasing the semiconductor efficiencies in the range $20-30 \%$ [4]. Other way to modify the band gap consists of creating a new valence band (VB) employing elements with orbitals different from the classical $\mathrm{O}_{2 p}$ of oxides. In this sense, different metallates have been evaluated as promising photocatalysts for visible light absorption [1]. These materials are metal oxides with $\mathrm{d}^{0}$ transition metals and $\mathrm{ns}^{2}$ cations, and with lower band gap values capable of generating charge carriers to be involved in redox reactions $[2,3,5]$. However, these semiconductors have some disadvantages, such as poor textural properties, structural heterogeneity and high particle size, mainly caused by the synthesis procedures conventionally employed. Thus, currently trends attempt to find novel synthesis ways to control the morphology and structure of these photocatalysts and to enhance their photoefficiency under solar light. 
Following our previous works on the performance of visiblelight driven photocatalysts [4,5], this article will, therefore, concentrate on the synthesis of silver vanadates by a soft chemistry method testing their photoefficiency and performing their postreaction characterization. Different routes to obtain silver vanadates have been reported avoiding the solid-state reaction route that requires high temperatures. For instance, highlight the hydrothermal, microwave-assisted or sonochemical methodologies [6,7], and more recently the preparation of hybrids, composites or thin films $[8,9]$. However, it is difficult to find a single suitable way for performing various metallates with different structure. This work will describe the synthesis of two silver vanadates, $\mathrm{AgVO}_{3}$ and $\mathrm{Ag}_{3} \mathrm{VO}_{4}$, by a microemulsion co-precipitation technique. This methodology is based on the preparation of reverse micelles in organic microemulsions $[10,11]$. The resulting materials should describe particle size in the nanometer range, narrow particle size distribution and homogeneous composition, and thus this methodology turns into an adequate way to get excellent catalysts. In this work, our emphasis will be focus on the study of their photocatalytic behavior and their post-reaction characterization.

\section{Experimental}

\subsection{Synthesis of silver vanadates $A g_{x} V O_{y}$}

Silver vanadates $\mathrm{Ag}_{x} \mathrm{VO}_{y}$ were prepared by a microemulsion technique. The reverse micelles were constituted by droplets of an aqueous solution encapsulated by a surfactant (Triton X-100) and a co-surfactant (1-hexanol), dispersed in n-heptane as oil [11]. For each silver vanadate $\left(\mathrm{AgVO}_{3}\right.$ and $\left.\mathrm{Ag}_{3} \mathrm{VO}_{4}\right)$, a microemulsion formed by an $\mathrm{NH}_{4} \mathrm{VO}_{3}$ aqueous solution was slowly added to other microemulsion with the $\mathrm{AgNO}_{3}$ salt (setting both metal concentrations to $0.5 \mathrm{M}$ ), avoiding the precipitation of silver oxide $\left(\mathrm{Ag}_{2} \mathrm{O}\right)$. The metal ratio $(\mathrm{Ag} / \mathrm{V})$ employed was adjusted to stoichiometric values. For the synthesis of $\mathrm{Ag}_{3} \mathrm{VO}_{4}$, the $\mathrm{pH}$ of the $\mathrm{NH}_{4} \mathrm{VO}_{3}$ solution was set to $12.5-13.0$ by adding a diluted TMAH solution just to favor the formation of vanadate ions $\left(\mathrm{VO}_{4}^{3-}\right)$. The precipitated was aged $24 \mathrm{~h}$ under continuous stirring. All microemulsions were covered with aluminum foil to prevent the reduction of $\mathrm{Ag}^{+}$. The resulting precipitated was separated and washed by centrifugation; dried at room temperature and heated at $110{ }^{\circ} \mathrm{C}$ overnight. The final samples were named $\mathrm{AgVO}_{3}$ and $\mathrm{Ag}_{3} \mathrm{VO}_{4}$.

\subsection{Characterization of the solids}

X-ray diffraction (XRD) analysis were recorded on a Seifert diffractometer at room temperature, using $\mathrm{Ni}$-filtered $\mathrm{Cu} \mathrm{K} \alpha$ radiation $(\lambda=0.15418 \mathrm{~nm})$ in the $2 \theta$ range $2-80^{\circ}$ with a scanning rate of $1.5 \mathrm{~min}^{-1}$. The structural identification of the substances has been accomplished by comparing with different databases, ICDD-JCPDS (Joint Committee on Powder Diffraction Standards, Swartmore, USA) and ICSD (Inorganic Crystal Structure Database, FIZ Karlsruhe, Germany). Surface areas were measured on a Micromeritics TriStar 123 system using the BET method from $\mathrm{N}_{2}$ adsorption-desorption isotherms at $-196^{\circ} \mathrm{C}$. Diffuse reflection spectra (DRS) were recorded on a UV-visible spectrometer (Shimadzu UV2100) in the 200-900 nm region using $\mathrm{BaSO}_{4}$ as standard. X-ray photoelectron spectra (XPS) were recorded on a VG Escalab 200R X-ray photoelectron spectrometer using an $\mathrm{Mg} \mathrm{K} \alpha \mathrm{X}$-ray $(1253.6 \mathrm{eV})$ as the excitation source and selecting $\mathrm{C} 1 \mathrm{~s}$ peak $(284.6 \mathrm{eV})$ as the reference line. Transmission electron microscopy (TEM) experiments were performed with a $200 \mathrm{kV} \mathrm{JEM}-2100 \mathrm{~F}$ (Jeol Ltd.) microscope equipped with an INCAx-Sight (Oxford Inc.) energy-dispersive Xray spectroscope (EDS). Energy spectra were analyzed with the Microanalysis INCA-EnergyTEM Suite v18.4.11 software package.
High Angle Annular Dark Field (HAADF) images were recorded in the same microscope by the STEM mode with a beam size of $1 \mathrm{~nm}$ and an inner collection angle of $68.5 \mathrm{mrad}$.

\subsection{Photocatalytic activity}

The photocatalytic degradation of Rhodamine $B(R h B)$ in aqueous solution was performed under visible light in a homemade reflective light box. Three daylight lamps of $40 \mathrm{~W}$ were used with an emission wavelength range of $400-700 \mathrm{~nm}$. The box was refrigerated by air and coated inside with reflective aluminium foil. RhB solution reactant $\left(25 \mathrm{mg} \mathrm{L}^{-1}\right)$ was first placed inside the batch reactor $(500 \mathrm{~mL})$ and then the catalyst powder $\left(500 \mathrm{mg} \mathrm{L}^{-1}\right)$ was added and dispersed by magnetic stirring. A steady stream of air $\left(100 \mathrm{~mL} \mathrm{~min}^{-1}\right)$ was blown inside solution to ensure the oxygen input. After $30 \mathrm{~min}$ in the dark to achieve the adsorption equilibrium, $10 \mathrm{~mL}$ of suspension were taken and filtered at given intervals. The RhB concentration was analyzed by a Shimadzu UV-2100 UV-visible spectrophotometer, monitoring the absorption peak at $554 \mathrm{~nm}$ characteristic of RhB. Duplicated runs were carried out for each catalyst to determine the reproducibility of the results and the experimental error was found within $6 \%$. The irradiation intensity of the lamps was measured with a radiometer Newpot (model $842-\mathrm{PE})$. The value for the maximum wavelength $(450 \mathrm{~nm})$ was $26.8 \mathrm{Wm}^{-2}$, used to calculate the photon flux. The catalysts were recovered after reaction by decantation, dried at $50{ }^{\circ} \mathrm{C}$ and characterized by the aforementioned techniques. The recovered catalysts were called used- $\mathrm{AgVO}_{3}$ and used- $\mathrm{Ag}_{3} \mathrm{VO}_{4}$.

\section{Results and discussion}

\subsection{Synthesis and characterization of silver vanadates}

The synthesis of silver vanadates is based on a microemulsion co-precipitation technique. This procedure has been employed for the synthesis of oxides, but its application to complex metallates has been less considered. By this technique, the silver vanadate precipitates inside small aqueous micelles by means of the interaction among the silver and vanadium solutions. The synthesis pathway was adapted to get the silver vanadates by controlling $\mathrm{pH}$, metal concentrations, time aging and temperature drying. Therefore, the methodology here detailed described the optimum conditions to get the coveted metallates, limiting the polymerization of vanadium ions and the precipitation of the silver oxides. The structural identification of the catalysts was followed by XRD, rejecting mixed and amorphous phases. The reproducibility of this synthesis was also tested, preparing several batches and following the crystallization by XRD, showing the formation of the desired metallate when the synthesis conditions were established. The diffratograms of the resulting silver vanadates are displayed in Fig. 1.

$\mathrm{AgVO}_{3}$ has acute polymorphism described by several authors $[12,13]$. In our work, the prepared $\mathrm{AgVO}_{3}$ exhibits an XRD diffractogram similar to that of $\alpha-\mathrm{AgVO}_{3}$ described by Kittaka et al. [13] with a monoclinic structure (Fig. 1A, ICSD pattern 50-645). This structure has only one kind of $\mathrm{V}^{5+}$ sites to build almost regular $\mathrm{VO}_{4}$ tetrahedron that formed zigzag chains by sharing the $\mathrm{O}^{2-}$ corner along $c$-axis. These $\mathrm{VO}_{4}$ chains are sandwiched between sheets of distorted $\mathrm{Ag}^{+}$octahedrons expanding to the c-direction by sharing the edges. By other side, the diffractogram of the $\mathrm{Ag}_{3} \mathrm{VO}_{4}$ (Fig. 1B) is analogous to that of $\alpha-\mathrm{Ag}_{3} \mathrm{VO}_{4}$ (JCPDS card No. 191154) described by Fleury [14] with a distorted "anti" sphaleritetype monoclinic structure. It describes a cubic close-packed arrangement of metal cations with the $\mathrm{O}^{2-}$ filling half of the tetrahedral positions. Thus, $\mathrm{Ag}^{+}$exhibits two different coordination 


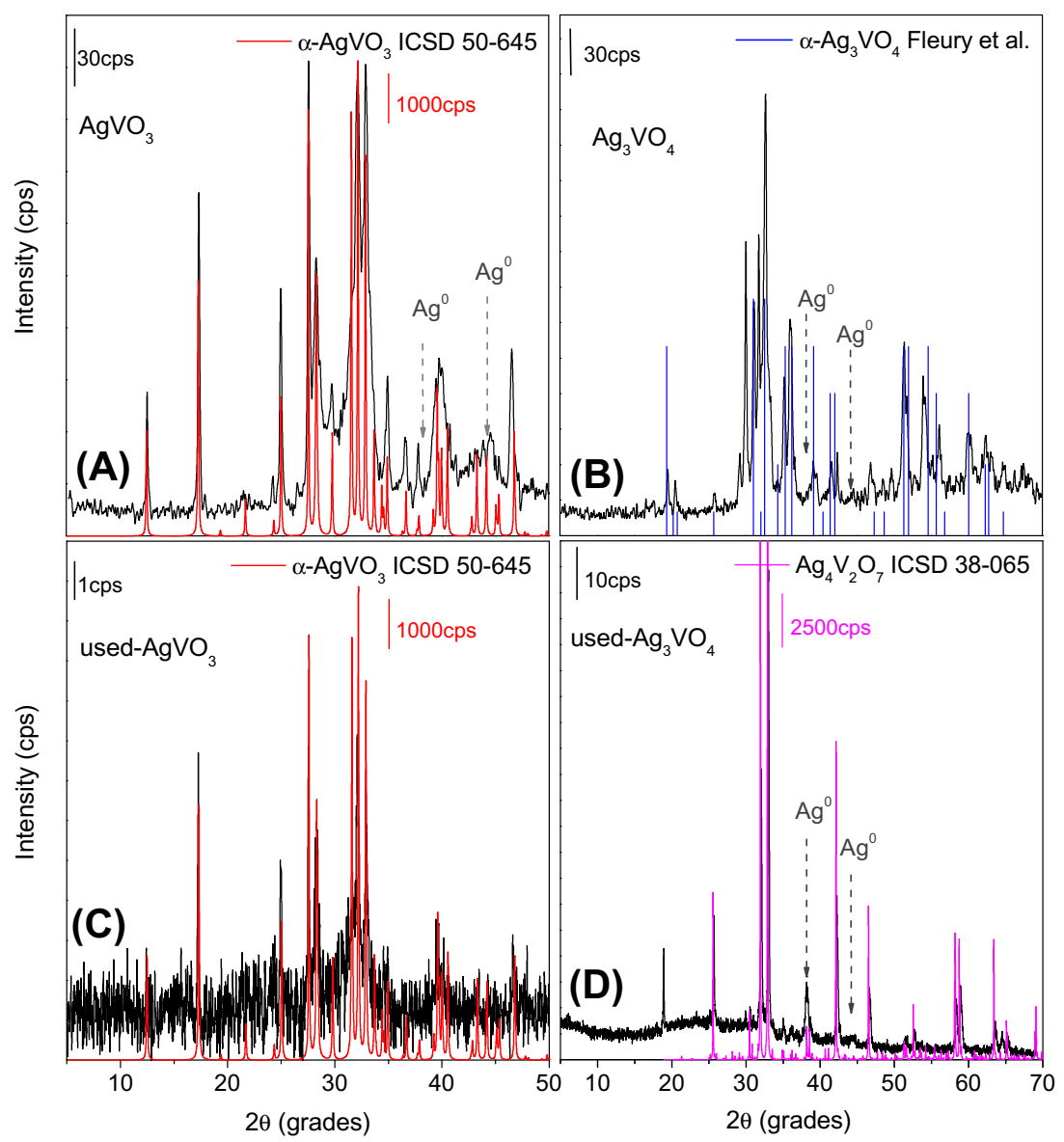

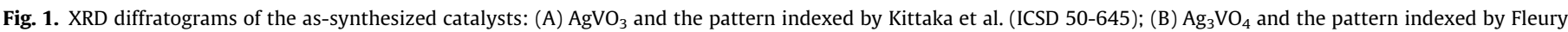

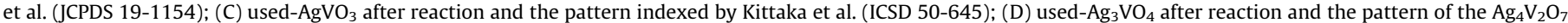
indexed (ICSD 38-065). The gray arrows indicate the position of silver crystals.

spheres, distorted square planar and pseudo-see-saw arrangement, while vanadium is tetrahedrally coordinated to four oxide anions.

In spite of the diffraction patterns match reasonably well with the indexed structures (Fig. 1), the experimental patterns were compared with different standards, just to mention the $\mathrm{Ag}^{0}$ and $\mathrm{Ag}_{2} \mathrm{O}$, detected by other authors $[15,16]$. $\mathrm{Ag}^{0}$ crystals should exhibit characteristic diffraction lines at $38.1^{\circ}$ and $44.2^{\circ} 2 \theta$ values, while the most intense diffraction lines of $\mathrm{Ag}_{2} \mathrm{O}$ appear at $32.9^{\circ}$ and $38.0^{\circ} 2 \theta$ values. The XRD diffractograms of both vanadates show diffraction lines at similar $2 \theta$ values to those of $\mathrm{Ag}^{0}$, but they overlap with the lines of the own silver vanadate and their intensity are very low to be assigned as $\mathrm{Ag}^{0}$ phase. Further to the structural characterization, the crystal size was calculated by the Scherrer's formula as the average of at least five intense diffraction peaks. The values are 28 and $20 \mathrm{~nm}$ for the $\mathrm{AgVO}_{3}$ and $\mathrm{Ag}_{3} \mathrm{VO}_{4}$, respectively. Thus, microemulsion technique gives rise to wellcrystallized silver vanadates at nanometric scale. The specific surface area of these systems was also measured. The values are 2.9 and $14.0 \mathrm{~m}^{2} \mathrm{~g}^{-1}$ for $\mathrm{AgVO}_{3}$ and $\mathrm{Ag}_{3} \mathrm{VO}_{4}$, respectively, considerably small provided that the crystal size is at nanometric scale. These low values suggest the formation of crystal aggregates that will be further described by microscopy techniques. The optical absorption properties of the catalysts were investigated by DRS-UV-vis spectroscopy (spectra shown in Fig. 1S at Supplementary data). Both silver vanadates show UV and visible light absorption at 400-520 nm, but the absorption edge overlaps with a shoulder at $550 \mathrm{~nm}$ that suggests the presence of $\mathrm{Ag}^{0}$ whose surface plasmon absorption increases the absorption in the visible range $[15,17]$. The presence of $\mathrm{Ag}^{0}$ was no detected by XRD characterization so it will be discussed later by other techniques. Owing to the shape of the DRS-UV-vis spectra of both silver vanadates, the band gap was estimated from the onset of the absorption edges (Table 1) [18]. The values calculated by the edge extrapolation are 2.26 and $1.95 \mathrm{eV}$ for $\mathrm{AgVO}_{3}$ and $\mathrm{Ag}_{3} \mathrm{VO}_{4}$ respectively, slightly lower than the values reported by other authors $[6,18]$ but adequate for visible-light driven photocatalysis.

X-ray photoelectron spectroscopy has been used to study the surface element composition of the catalysts. The Ag $3 d$ spectra of both catalysts are plotted in Fig. 2S, at Supplementary data, showing two main peaks, $\mathrm{Ag} 3 d_{5 / 2}$ and $\mathrm{Ag} 3 d_{3 / 2}$. The $\mathrm{Ag} 3 d_{5 / 2}$ peak deconvolution results in two Gaussian components at 368.2 and $367.4 \mathrm{eV}$ for the $\mathrm{AgVO}_{3}$ and 368.5 and $367.1 \mathrm{eV}$ for the $\mathrm{Ag}_{3} \mathrm{VO}_{4}$ that correspond with $\mathrm{Ag}^{0}$ and $\mathrm{Ag}^{+}$ions, respectively [19,20]. The different shifts described by the silver components are mainly due to the different chemical environment of the silver in each structure. Although both silver vanadates describe a monoclinic structure, the $\mathrm{Ag}^{+}$occupies different coordination positions, $\mathrm{Oh}$ and $\mathrm{Td}$ for $\mathrm{AgVO}_{3}$ and $\mathrm{Ag}_{3} \mathrm{VO}_{4}$, respectively. The results of the estimated composition at surface analyzed from XPS are given in Table 1. The $\mathrm{AgVO}_{3}$ is composed of $71 \% \mathrm{Ag}^{+}$and $29 \% \mathrm{Ag}^{0}$, while the $\mathrm{Ag}_{3} \mathrm{VO}_{4}$ is formed by $41 \% \mathrm{Ag}^{+}$and $59 \% \mathrm{Ag}^{0}$ at surface. XPS analyses further confirm the presence of $\mathrm{Ag}^{0}$ that has been previously proposed by the UV-visible spectroscopic characterization. The $\mathrm{Ag}^{0}$ formation at surface could be associated with the photosensitivity of $\mathrm{Ag}^{+}$, though care was taken during synthesis handling of the catalysts was not performed in complete darkness, so the reduction by light could occur. The surface atomic ratios (estimated from XPS spectra) and the bulk metal ratios (determined by EDS) are also 
Table 1

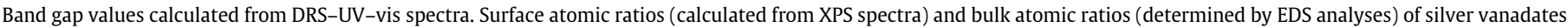

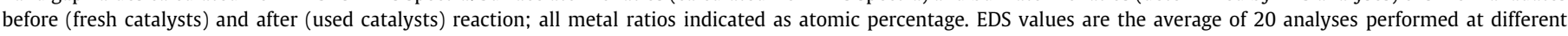
regions.

\begin{tabular}{|c|c|c|c|c|c|c|c|c|c|c|c|}
\hline \multirow[t]{3}{*}{ Sample } & \multirow[t]{3}{*}{ Band gap (eV) } & \multicolumn{5}{|c|}{ Fresh catalysts } & \multicolumn{5}{|c|}{ Used catalysts $^{\mathrm{a}}$} \\
\hline & & \multicolumn{4}{|c|}{ Surface atomic ratios XPS } & \multirow{2}{*}{$\begin{array}{l}\text { Bulk atomic ratios EDS } \\
\mathrm{Ag} / \mathrm{V}\end{array}$} & \multicolumn{4}{|c|}{ Surface atomic ratios XPS } & \multirow{2}{*}{$\begin{array}{l}\text { Bulk atomic ratios EDS } \\
\mathrm{Ag} / \mathrm{V}\end{array}$} \\
\hline & & $\begin{array}{l}\mathrm{Ag}_{3 \mathrm{~d}} / \\
\mathrm{V}_{2 \mathrm{p}}\end{array}$ & $\begin{array}{l}\mathrm{O}_{1 \mathrm{~s}} / \\
\mathrm{V}_{2 \mathrm{p}}{ }^{\mathrm{b}}\end{array}$ & $\begin{array}{l}\mathrm{O}_{1 \mathrm{~s}} / \\
\mathrm{Ag}_{3 \mathrm{~d}} \mathrm{~b}\end{array}$ & ${ }^{\mathrm{c}} \mathrm{Ag}^{0}(\%)$ & & $\begin{array}{l}\mathrm{Ag}_{3 \mathrm{~d}} / \\
\mathrm{V}_{2 \mathrm{p}}\end{array}$ & $\begin{array}{l}\mathrm{O}_{1 \mathrm{~s}} / \\
\mathrm{V}_{2 \mathrm{p}}{ }^{\mathrm{b}}\end{array}$ & $\begin{array}{l}\mathrm{O}_{1 \mathrm{~s}} / \\
\mathrm{Ag}_{3 \mathrm{~d}} \mathrm{~b}\end{array}$ & ${ }^{\mathrm{c}} \mathrm{Ag}^{0}(\%)$ & \\
\hline $\mathrm{AgVO}_{3}$ & 2.26 & 2.3 & 3.9 & 1.8 & 29 & 1.3 & 2.4 & 7.3 & 3.1 & 22 & 1.6 \\
\hline $\mathrm{Ag}_{3} \mathrm{VO}_{4}$ & 1.95 & 7.0 & 7.4 & 1.5 & 59 & 2.8 & 4.4 & 9.8 & 1.2 & 53 & 2.9 \\
\hline
\end{tabular}

a Catalysts recovered after reaction.

b Oxygen/metal ratios calculated excluding the effect caused by the surface hydroxyl species.

c Metallic silver concentration at surface.

shown in Table 1. From these data, it can be appreciated that the silver/vanadium ratios $(\mathrm{Ag} / \mathrm{V})$ at surface exceed, in both solids, the theoretical bulk Ag/V ratios. About the oxygen/metal ratios at surface, the main difference with the theoretical values is the amount of vanadium at surface. The $\mathrm{O} / \mathrm{V}$ ratio is higher than expected, suggesting that both samples are deficient in vanadium at surface. This Ag enrichment and V depletion at surface could be related to some $\mathrm{Ag}$ segregation from the silver vanadate, due to the evolution of $\mathrm{Ag}^{+}$to $\mathrm{Ag}^{0}$ at surface abovementioned. The presence of $\mathrm{Ag}^{0}$ will be further discussed with the support of microscopy tools.

Silver vanadates were characterized by TEM, HAADF-STEM and EDS although they are beam sensitive materials. Silver vanadates are indeed modified by the electron beam depending on time and energy of the exposure as has been reported by Singh et al. [7]. The main results about the evolution of the $\mathrm{Ag}_{3} \mathrm{VO}_{4}$ are described in the Supplementary data (Fig. 3S). Nevertheless, it was possible to control the effect of the electron beam and the solids were evaluated by these techniques. $\mathrm{AgVO}_{3}$ particles are star-like shape grains, from 1 to $10 \mu \mathrm{m}$ of size, made up of aggregation of smaller particles (Fig. 2A, and Fig. $4 \mathrm{~S}$ and $5 \mathrm{~S}$ at Supplementary data). Fig. $2 \mathrm{~B}$ shows one of these grains faced perpendicular to the plot lane. The particle was scanned along the yellow line recording the respective EDS spectra. The energy lines of the elements, $\mathrm{V}-\mathrm{K}_{\alpha 1}, A g-\mathrm{L}_{\alpha 1}$ and $\mathrm{O}-\mathrm{K}_{\alpha 1}$, are also plotted along the scanned direction. The brighter regions in HAADF-STEM images are usually related to the presence of an element with higher mean $Z$ value at constant thickness. However, in this case, the aggregation of particles yields to regions with different thickness and we cannot conclude that the brighter regions are due to $\mathrm{Ag}$ presence. By other side, it can be seen that the energy lines of both $\mathrm{Ag}$ and $V$ follow the same trend, increasing their intensities in the thicker regions. Thus, Ag and V are apparently homogeneously distributed on the star-like grains and the brighter regions correspond to thicker regions (to compare other particles are included in Supplementary data, Fig. 5S(C and D). Higher magnification images of the $\mathrm{AgVO}_{3}$ grains were obtained by TEM and STEM techniques Fig. 2C (and Figs. 4S(C-F) and 5S(E and F) at Supplementary data). This characterization reveals the presence of small particles at the surface of these micrometric star-shaped grains. The brightness could be indicative of higher silver composition that can be related to the presence of $\mathrm{Ag}^{0}$ at surface, described above by XPS analyses but unnoticed by XRD due to the low percentage ascribable to this phase. The particle size distribution of these small particles has been calculated (Fig. 2D) showing a unimodal distribution with a mean particle size of $6.0 \pm 2.0 \mathrm{~nm}$.

The $\mathrm{Ag}_{3} \mathrm{VO}_{4}$ microscopy characterization is shown in Fig. 3 (and Figs. $6 \mathrm{~S}$ and $7 \mathrm{~S}$ at Supplementary data). $\mathrm{Ag}_{3} \mathrm{VO}_{4}$ particles are heterogeneous aggregates with a globular appearance made up of submicrometric size particles (Fig. 3A). The $\mathrm{V}-\mathrm{K}_{\alpha 1}, \mathrm{Ag}-\mathrm{L}_{\alpha 1}$ and $\mathrm{O}-\mathrm{K}_{\alpha 1}$ energy lines have been scanned along the yellow line drawn in the figures (Fig. 3B and Fig. 7S(D and E)). These profiles show certain heterogeneity when different particles are compared. Fig. 3B describes a particle with the same trend for both $\mathrm{Ag}$ and $\mathrm{V}$ energy lines, while the particles shown in Fig. 7S(D and E) depict regions where the silver line intensity is higher than the vanadium one, suggesting the creation of silver particles. Higher magnification images (Fig. 3C and Fig. $6 \mathrm{~S}$ ) reveal the presence of small particles at surface that can be related to $\mathrm{Ag}^{0}$ nanoparticles, detected by XPS and also observed for the $\mathrm{AgVO}_{3}$. The particle size distribution of these small particles has been plotted in Fig. 3D, describing a unimodal distribution with a mean particle size of $7.3 \pm 5.2 \mathrm{~nm}$. Thus, the microemulsion methodology yields to silver vanadates decorated at surface with (XRD-silent; e.g. a relatively minor phase) nanoparticles of metallic silver.

\subsection{Photocatalytic degradation of $R h B$}

The photocatalytic behavior of silver vanadates was evaluated by the photodegradation of Rhodamine $\mathrm{B}(\mathrm{RhB})$, a dye widely studied as a representative water pollutant [5]. Fig. 4A and $B$ shows time profiles of $\mathrm{RhB}$ concentration and $\ln \left[C / C_{0}\right]$ vs. irradiation time for both vanadates, being $C$ the concentration of $R h B$ at each reaction time and $C_{0}$ the initial concentration in the adsorption equilibrium. These plots describe a linear decrease that can be fitted for pseudo-first-order kinetics. Thus, the reaction rate constant calculated for $\mathrm{AgVO}_{3}$ and $\mathrm{Ag}_{3} \mathrm{VO}_{4}$ was $8.9 \times 10^{-4} \mathrm{~min}^{-1}$ and $5.5 \times 10^{-2}$ $\mathrm{min}^{-1}$, respectively. The $\mathrm{Ag}_{3} \mathrm{VO}_{4}$ exhibits the highest photoactivity ( 2 orders of magnitude higher than the other catalyst) and a $98 \%$ $\mathrm{RhB}$ reduction by completing $1 \mathrm{~h}$ experiment, while the $\mathrm{AgVO}_{3}$ exhibits a conversion value ca. to $26 \%$. The photolysis degradation of RhB was also tested, yielding to low conversion values and proving the high removal efficiency of the $\mathrm{Ag}_{3} \mathrm{VO}_{4}$ photocatalyst. The relative photonic efficiency $(\xi)$ was determined according to Serpone [21], being the photon flux $1.00 \times 10^{-6}$ einsteins $\mathrm{s}^{-1}$. The $\xi$ values were 0.052 and 5.48 molRhB einsteins ${ }^{-1}$ for $\mathrm{AgVO}_{3}$ and $\mathrm{Ag}_{3-}$ $\mathrm{VO}_{4}$, respectively, showing once again that the $\mathrm{Ag}_{3} \mathrm{VO}_{4}$ describes the best photoefficiency. The temporal evolutions of the spectral changes that occur during the RhB degradation are also shown in Fig. 8S at Supplementary data. The maximum absorption of RhB decreases during the irradiation time and consecutively undergoes a shifting to lower wavelength values, which is more evident for the $\mathrm{Ag}_{3} \mathrm{VO}_{4}$ catalyst. According to the $\mathrm{RhB}$ degradation mechanisms reported in literature, this blue shift in the absorption band of the dye is caused by the N-deethylation of the RhB, yielding to de-ethylated RhB products which light absorption maximum appears at $498 \mathrm{~nm}$ [22]. Therefore, in the case of $\mathrm{Ag}_{3} \mathrm{VO}_{4}$ catalyst, apart from the degradation of the chromophore ring, the N-deethylation process had taken place by the end of the experiment.

$\mathrm{Ag}_{3} \mathrm{VO}_{4}$ catalyst apparently displays the highest activity, reaching more than $90 \%$ conversion values in a short time. The first approach to explain this activity is based on the physic-chemical 

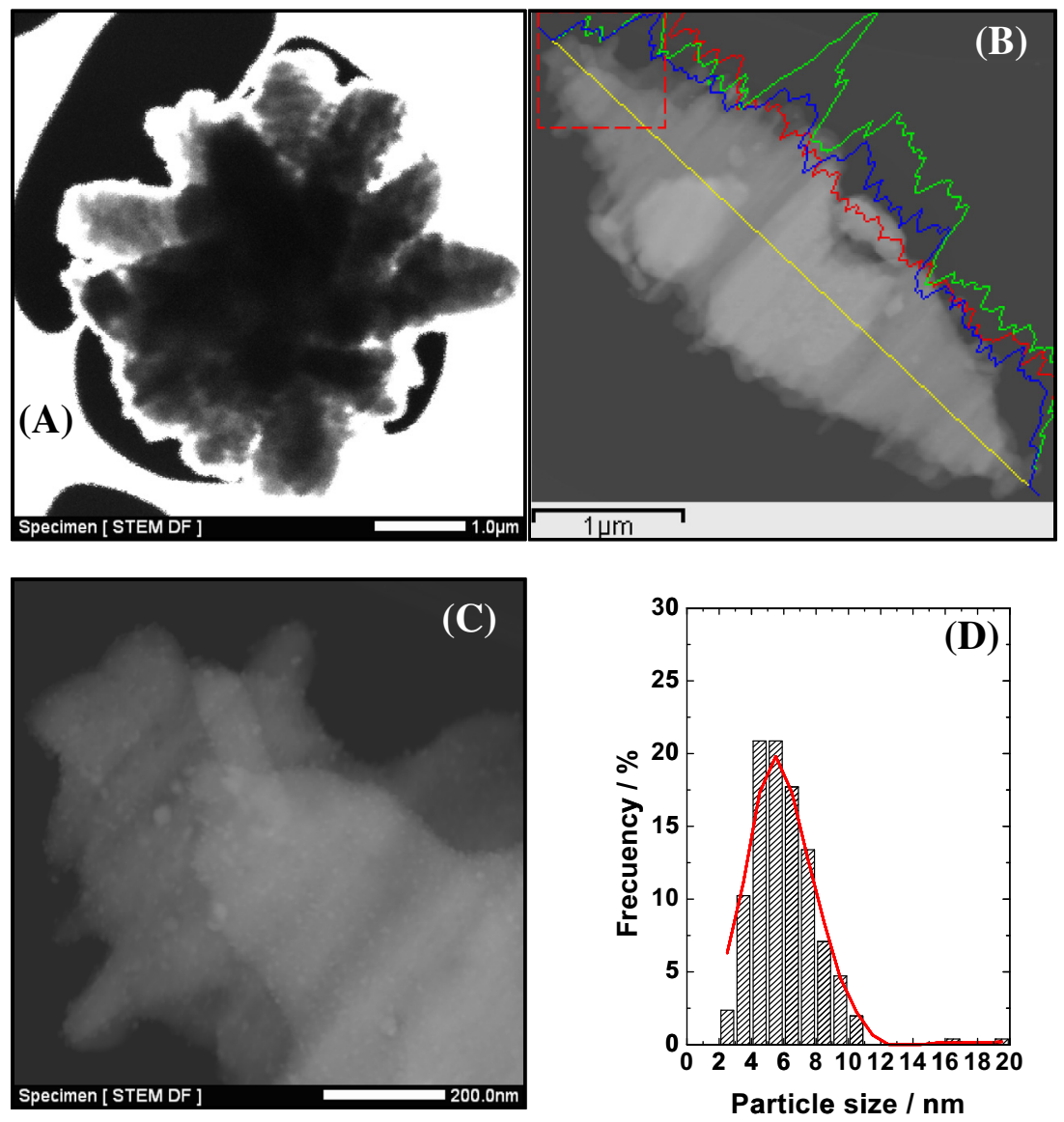

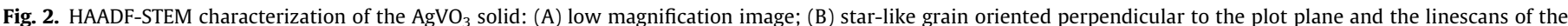

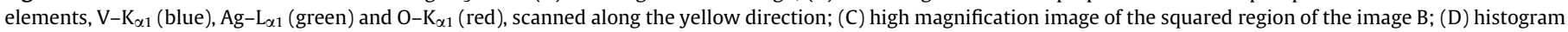
of the Ag-metal particle size distribution. (For interpretation of the references to color in this figure legend, the reader is referred to the web version of this article.)

properties of this catalyst. Thus, the larger surface area, the lowest band gap value $(1.95 \mathrm{eV})$ and the higher absorption power in the visible region are apparently in line with the high potential for photodegradation shown by the material. Even, it has been reported that the holes photogenerated in $\mathrm{Ag}_{3} \mathrm{VO}_{4}$ can migrate to the reaction sites at surface easier than those of other silver vanadates [18]. However, the presence of $\mathrm{Ag}^{0}$ nanoparticles detected at surface must be considered as an additional factor. It is known that metallic silver can play double-dealing. It can enhance the separation of electron-hole pairs leading to high photoefficiency, or act as recombination centre being detrimental for the photoactivity [15]. Therefore, the survey about the factors involved in the photoactivity of the silver vanadates was extended to the characterization of the catalysts after reaction. The recovered catalysts (named usedcatalysts) were characterized by XRD, XPS, TEM and STEM. The results obtained from these analyses have provided new information about the factors involved in the photoactivity of the $\mathrm{Ag}_{3} \mathrm{VO}_{4}$ catalyst and will be described in next section.

\subsection{Characterization of the used silver vanadates after reaction}

The XRD diffractograms of the used silver vanadates after reaction are plotted in Fig. 1 beside the diffractograms before reaction. The structure of the $\mathrm{AgVO}_{3}$ catalyst remains after reaction, although with a poor signal because the low amount of catalyst recovered. Nonetheless, the $\mathrm{Ag}_{3} \mathrm{VO}_{4}$ catalyst suffers important structural changes. The original peaks assigned to the anti-sphalerite structure disappear, appearing in place new ones that can be indexed to orthorhombic pyrovanadate $\mathrm{Ag}_{4} \mathrm{~V}_{2} \mathrm{O}_{7}$ (ICSD 38-065) [23]. The used- $\mathrm{Ag}_{3} \mathrm{VO}_{4}$ diffractogram also exhibits peaks at 38.1 and $44.2^{\circ}(2 \theta)$ that are assigned to the presence of $\mathrm{Ag}^{0}$ crystals. We must remember that these $\mathrm{Ag}^{0}$ crystals were no detected by XRD in the original $\mathrm{Ag}_{3} \mathrm{VO}_{4}$ catalyst (Fig. 1B). Then, the photocatalytic reaction causes the $\mathrm{Ag}_{3} \mathrm{VO}_{4}$ transformation to $\mathrm{Ag}_{4} \mathrm{~V}_{2} \mathrm{O}_{7}$ with $\mathrm{Ag}^{0}$ crystals, while the $\mathrm{AgVO}_{3}$ remains without structural changes.

The HAADF-STEM images of used-AgVO ${ }_{3}$ catalyst are shown in Fig. 5A and B and TEM images in Supplementary data (Fig. 9S(A and $\mathrm{B})$ ). The morphology of the $\mathrm{AgVO}_{3}$ particles changes during reaction. The star-like grains disappear probably because the impacts with the magnetic stirrer. The images reveal the formation of greater $\mathrm{Ag}^{0}$ particles at surface after reaction (not detected by XRD because the low intensity of the diffractogram). These particles describe a size distribution less homogeneous than the original $\mathrm{AgVO}_{3}$ (Fig. 5C), with particles of $10 \mathrm{~nm}$ and higher particles in the $10-30 \mathrm{~nm}$ region. The bulk and surface $\mathrm{Ag} / \mathrm{V}$ ratios of the used$\mathrm{AgVO}_{3}$ solid are shown in Table 1 . The percentage of $\mathrm{Ag}^{0}$ at surface is almost unchanged after reaction (29\% for $\mathrm{AgVO}_{3}$ and $22 \%$ for used- $\mathrm{AgVO}_{3}$ ). This value suggests that the size increase of the $\mathrm{Ag}^{0}$ particles at surface is caused by the aggregation of the original silver nanoparticles detected on the $\mathrm{AgVO}_{3}$. Thus, the reaction causes the creation of $\mathrm{Ag}^{0}$ aggregates while its structure is essentially stable. The STEM images of the used- $\mathrm{Ag}_{3} \mathrm{VO}_{4}$ catalyst are also shown in Fig. 5D and $\mathrm{E}$ and the respective TEM images in Supplementary data (Fig. 9S(C and D)). The $\mathrm{Ag}_{3} \mathrm{VO}_{4}$ particles describe a regular polyhedron shape after reaction that is related to the formation of a new phase. Higher magnification images (Fig. 5E 9S) reveal the presence of large $\mathrm{Ag}^{0}$ particles that now are even detected by $\mathrm{XRD}$. The particle size distribution of these $\mathrm{Ag}^{0}$ particles is plotted in Fig. 5F. It shows particles in the low region $(<10 \mathrm{~nm})$ and greater particles close to $18 \mathrm{~nm}$. In addition, the $\mathrm{Ag}^{0}$ percentages at surface 

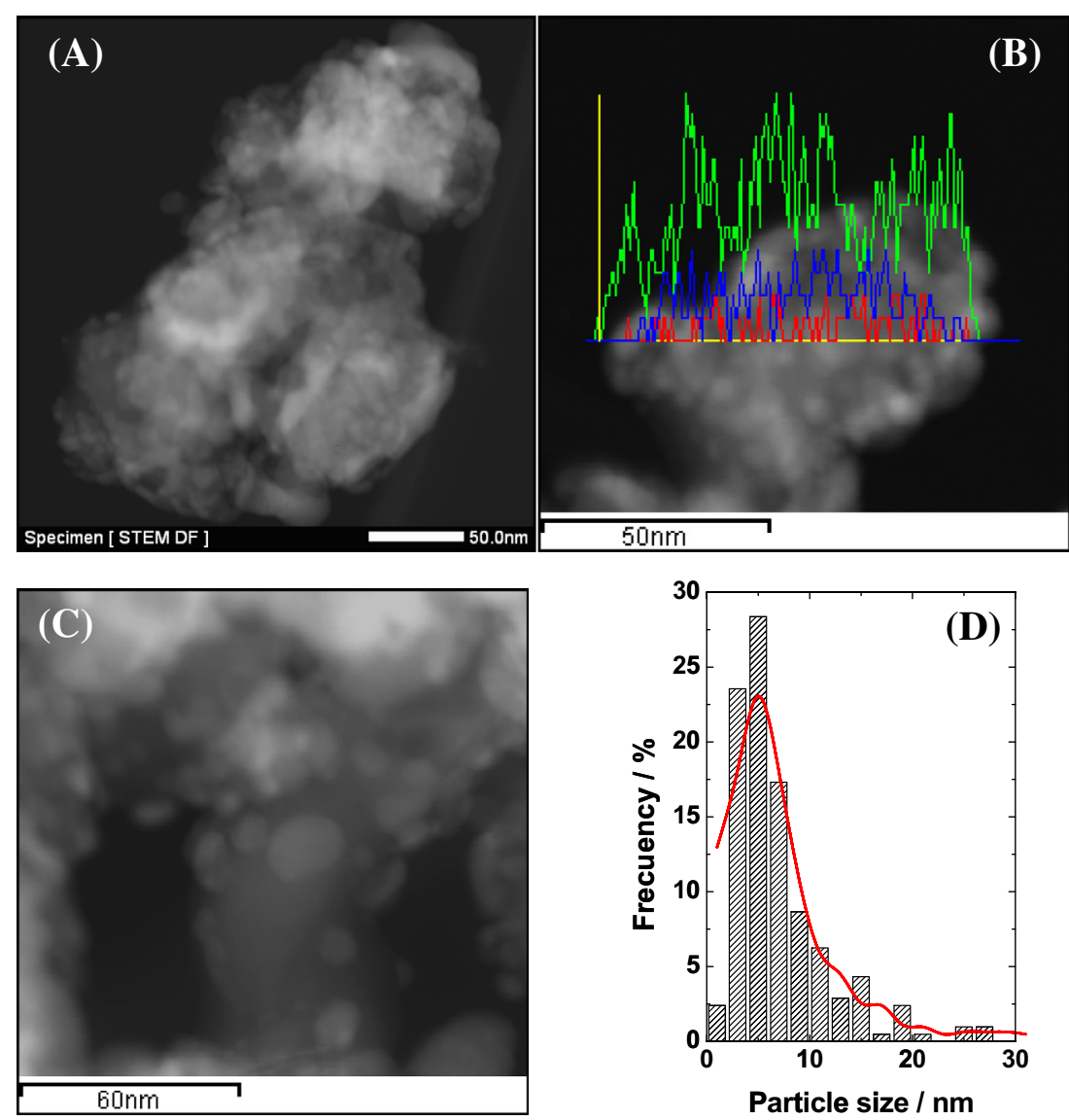

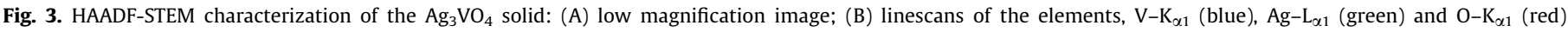

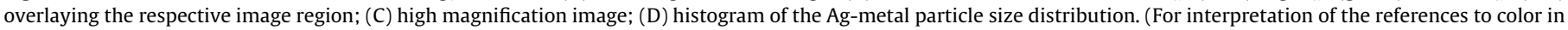
this figure legend, the reader is referred to the web version of this article.)
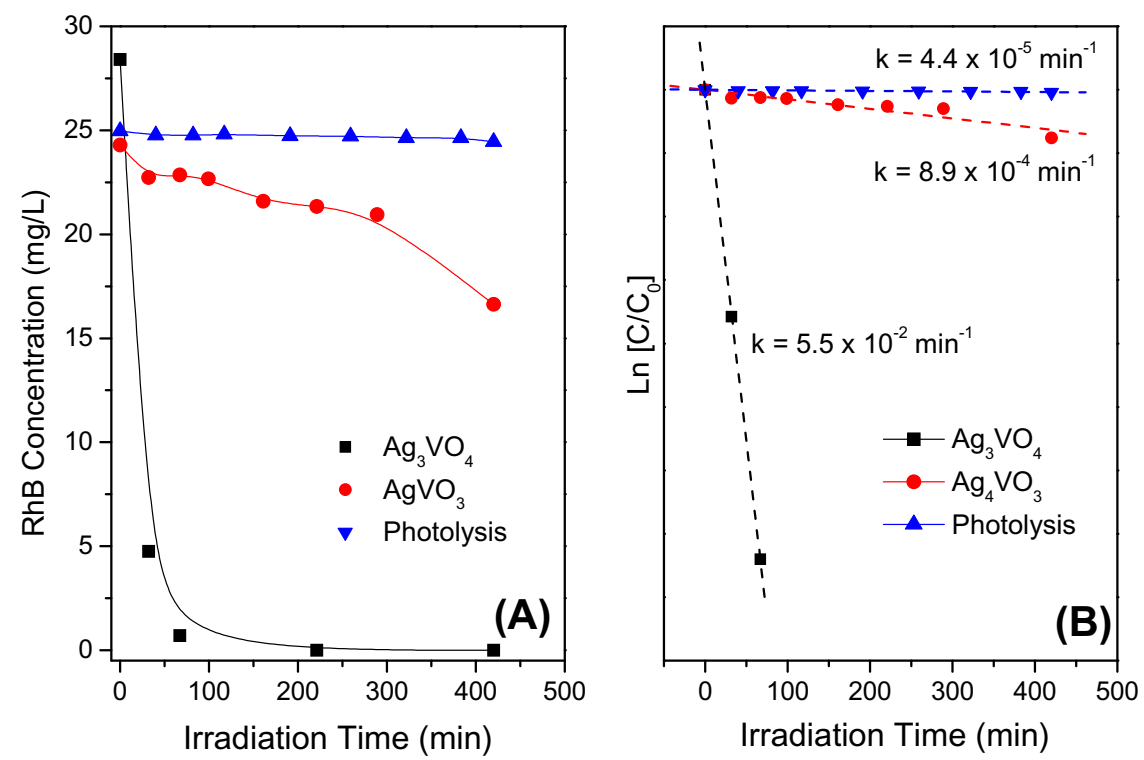

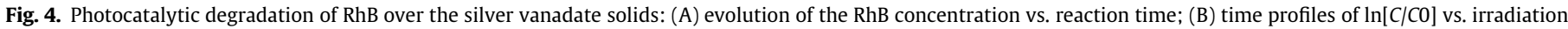
time. Reaction conditions: $V_{\text {reactor }}=1 \mathrm{~L}, \mathrm{pH}=6,[\mathrm{RhB}]=25 \mathrm{mg} \mathrm{L}^{-1}$, [Catalyst $]=500 \mathrm{mg} \mathrm{L}^{-1},\left[\mathrm{O}_{2}\right]=100 \mathrm{~cm}^{3} \mathrm{~min}^{-1}$.

remains roughly constant thought the reaction (see Table 1 ) then the particle size increase should be caused by the sinterization of the $\mathrm{Ag}^{0}$ particles initially present at surface. Silver lixiviation during photocatalytic degradation have been evaluated by EDS. As it has been described before, several particles were scanned record- ing the respective EDS spectra. Mean atomic $\mathrm{Ag} / \mathrm{V}$ ratios measured on several parts of the used samples were 1.6 and 2.8, for $\mathrm{AgVO}_{3}$ and $\mathrm{Ag}_{3} \mathrm{VO}_{4}$, respectively (see Table 1 ). These values indicate a slightly silver enrichment compared to the mean atomic $\mathrm{Ag} / \mathrm{V}$ ratios of the fresh samples. The highest difference is up to $5 \%$ that lies 

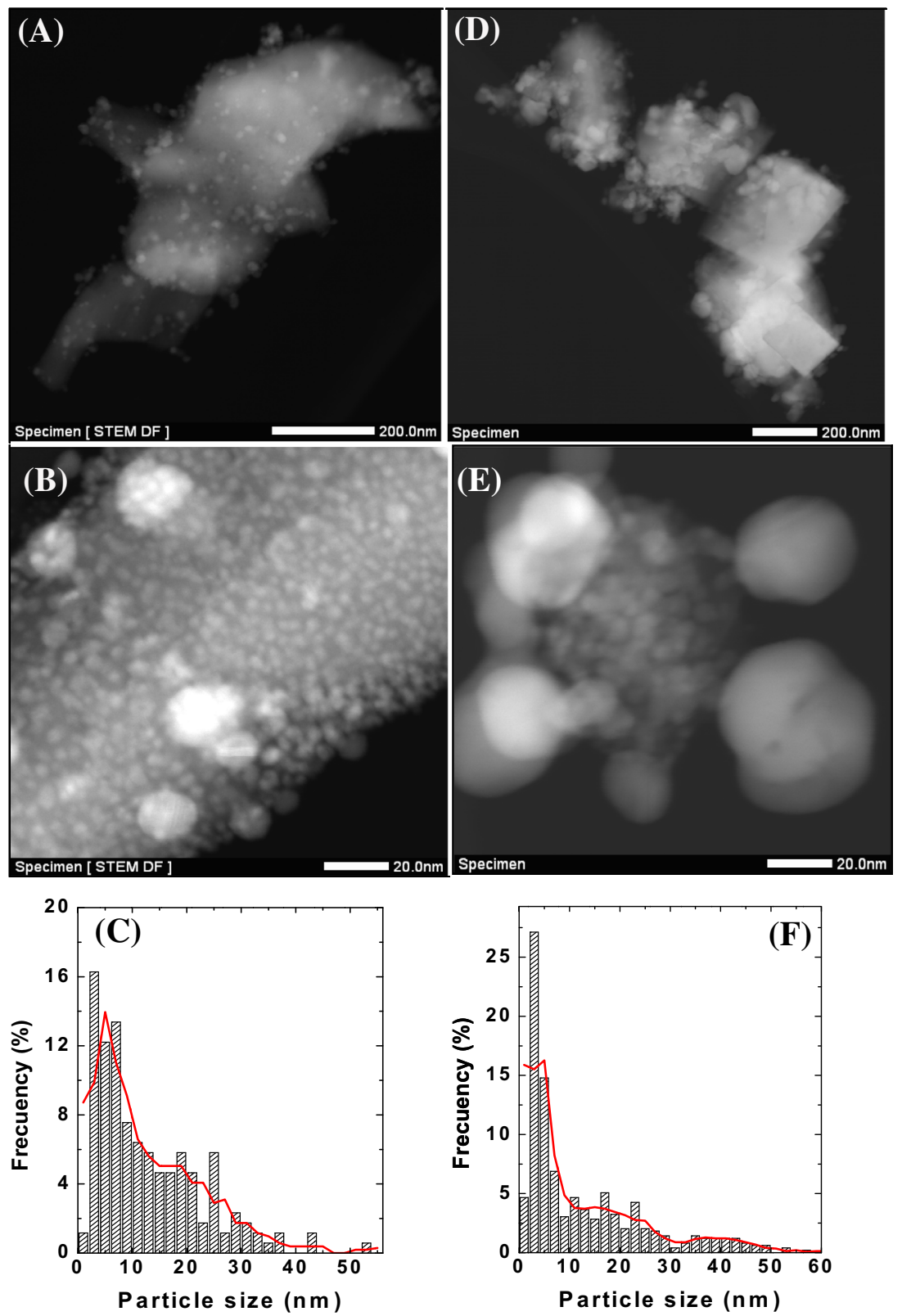

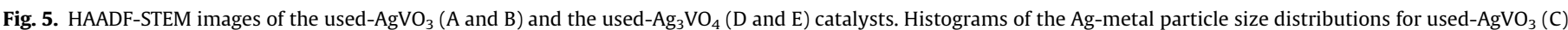
and used- $\mathrm{Ag}_{3} \mathrm{VO}_{4}(\mathrm{~F})$ catalysts.

within the error of this technique. Accordingly, significant silver lixiviation can be discarded. Samples do only suffer the changes in crystal structure and phase segregation mentioned before. Therefore, the aforementioned origin of the photocatalytic activity of $\mathrm{Ag}_{3} \mathrm{VO}_{4}$ must be reconsidered taking into account the information obtained after reaction. It seems obvious thinking that the explanation of the activity obtained for this catalyst is closer to structural changes that occur during the photocatalytic reaction and due to the behavior of the silver nanoparticles more than to the initial physic-chemical properties of the solid.

The results here described cannot explain in detail the structural change observed on the $\mathrm{Ag}_{3} \mathrm{VO}_{4}$ catalyst during reaction. However, our XRD, XPS and STEM results have demonstrated that initially the $\mathrm{Ag}_{3} \mathrm{VO}_{4}$ solid has the $\alpha-\mathrm{Ag}_{3} \mathrm{VO}_{4}$ crystal structure decorated with $\mathrm{Ag}^{0}$ nanoparticles at surface. We thus suggest that under reaction conditions the silver vanadate is unstable and can be converted to pyrovanadate accompanied by a small amount, possibly amorphous, of $\mathrm{Ag}_{2} \mathrm{O}$, following the reaction above indicated:
$\mathrm{Ag}^{0}+2 \mathrm{Ag}_{3} \mathrm{VO}_{4} \rightarrow \mathrm{Ag}_{4} \mathrm{~V}_{2} \mathrm{O}_{7}+\mathrm{Ag}_{2} \mathrm{O}+\mathrm{Ag}^{0}$

By this hypothesis, a new vanadate phase is fomed at the end of the reaction together with a redox couple system $\mathrm{Ag}_{2} \mathrm{O} / \mathrm{Ag}^{0}$ that can be activated by visible light. In this line, the stability to visible-light of other silver photocatalysts has been recently analyzed. For instance, Wang et al. [24] have been reported the photocatalytic properties of $\mathrm{Ag}_{2} \mathrm{O} / \mathrm{Ag}^{0}$ systems. They observed that $\mathrm{Ag}_{2} \mathrm{O}$ is unstable under visible-light and decomposes during the photocatalytic degradation of organic substances. The $\mathrm{Ag}^{+}$of the $\mathrm{Ag}_{2} \mathrm{O}$ is reduced in situ by photogenerated electrons and forms $\mathrm{Ag}^{0}$ during the photocatalytic experiments. These authors also detailed that the $\mathrm{Ag}^{0}$ particles can act as photocatalytic centers, capturing the photogenerated electrons and transferring them to the oxygen of the medium. This synergistic effect has been also detailed by other silver visible-light systems. In addition, in the aforementioned reference [24] the high photoefficiency of the $\mathrm{Ag}_{2} \mathrm{O} / \mathrm{Ag}^{0}$ couple was 
demonstrated, with stable activity after five consecutive catalytic tests. In conclusion, although the original catalyst is modified during the reaction it describes high photocatalytic activity. In our work, unfortunately, the preparation of $\mathrm{Ag}_{4} \mathrm{~V}_{2} \mathrm{O}_{7}$ by microemulsion methodology was not possible, but it has been reported that this pyrovanadate is photoactive under visible light [6]. In our case, although the $\mathrm{Ag}_{3} \mathrm{VO}_{4}$ is modified during reaction, the formation of pyrovanadate active phase and the presence of $\mathrm{Ag}_{2} \mathrm{O} / \mathrm{Ag}^{0}$ couple appear as the synergistic combination responsible of achieving a highly active system upon visible light excitation.

\section{Conclusions}

$\mathrm{AgVO}_{3}$ and $\mathrm{Ag}_{3} \mathrm{VO}_{4}$ vanadates were successfully synthesized by a microemulsion methodology. The characterization revealed the formation of both silver vanadates decorated with silver metallic nanoparticles at surface. The as-prepared $\mathrm{Ag}_{3} \mathrm{VO}_{4}$ catalyst displayed high photocatalytic activity although suffered important structural changes during reaction. The initial structure was transformed in a silver pyrovanadate, $\mathrm{Ag}_{4} \mathrm{~V}_{2} \mathrm{O}_{7}$, with a concomitant size increase of the silver metallic particles decorating the surface. The synergistic combination between the $\mathrm{Ag}_{2} \mathrm{O} / \mathrm{Ag}^{0}$ nanoparticles and the photoactivity of the more stable $\mathrm{Ag}_{4} \mathrm{~V}_{2} \mathrm{O}_{7}$ phase seems to be responsible of the high photoactivity of this catalyst. Thus, the $\mathrm{Ag}_{3-}$ $\mathrm{VO}_{4} / \mathrm{Ag}^{0}$ photocatalyst could be a promising candidate for the removal of hazardous organic materials and its preparation with large specific surface areas and high pore volumes is highly sought.

\section{Acknowledgements}

The authors thank the funding from MICINN Project CTQ201014872/BQU. C.B. and C.A. are indebted to the MICINN for their respective Ramón y Cajal and Juan de la Cierva postdoctoral contracts.

\section{Appendix A. Supplementary material}

Supplementary data associated with this article can be found, in the online version, at http://dx.doi.org/10.1016/j.cej.2012.11.102.

\section{References}

[1] A. Kubacka, M. Fernández-García, G. Colón, Advanced nanoarchitectures for solar photocatalytic applications, Chem. Rev. 112 (2012) 1555-1614.

[2] C. Lettmann, H. Hinrichs, W.F. Maier, Combinatorial discovery of new photocatalysts for water purification with visible light, Angew. Chem. Int. Ed. 40 (2001) 3160-3164.
[3] M.D. Hernández-Alonso, F. Fresno, S. Suárez, J.M. Coronado, Development of alternative photocatalysts to $\mathrm{TiO}_{2}$ : challenges and opportunities, Energy Environ. Sci. 2 (2009) 1231-1257.

[4] A. Kubacka, B. Bachiller, G. Colón, M. Fernández García, Doping level effect on sunlight-driven $\mathrm{w}$, n-doped $\mathrm{Tio}_{2}$-anatase photocatalysts for aromatic hydrocarbon partial oxidation, Appl. Catal. B 93 (2010) 274-281.

[5] C. Belver, C. Adán, M. Fernández-García, Photocatalytic behavior of $\mathrm{Bi}_{2} \mathrm{MO}_{6}$ polymetalates for Rhodamine B degradation, Catal. Today 143 (2009) 274-281.

[6] C.-M. Huang, G.-T. Pan, Y.-C.M. Li, M.-H. Li, T.C.-K. Yang, Crystalline phases and photocatalytic activities of hydrothermal synthesis $\mathrm{Ag}_{3} \mathrm{VO}_{4}$ and $\mathrm{Ag}_{4} \mathrm{~V}_{2} \mathrm{O}_{7}$ under visible light irradiation, Appl. Catal. A - Gen. 358 (2009) 164-172.

[7] D.P. Singh, K. Polychronopoulou, C. Rebholz, S.M. Aouadi, Room temperature synthesis and high temperature study of silver vanadate nanorods, Nanotechnology 21 (2010) 325601-325608.

[8] H. Lin, P.A. Maggard, Synthesis and structures of a new series of silvervanadate hybrid solids and their optical and photocatalytic properties, Inorg. Chem. 47 (2008) 8044-8052.

[9] W.-S. Chang, Y.-C.M. Li, T.-W. Chung, Y.-S. Lin, C.-M. Huang, Toluene decomposition using silver vanadate/SBA-15 photocatalysts: DRIFTS study of surface chemistry and recyclability, Appl. Catal. A - Gen. 407 (2011) 224-230.

[10] V. Uskokovic, M. Drofenik, Synthesis of materials within reverse micelles, Surf. Rev. Lett. 12 (2005) 239-277.

[11] M. Fernández-García, C. Belver, J.C. Hanson, X. Wang, J.A. Rodriguez, Anatase$\mathrm{TiO}_{2}$ nanomaterials: analysis of key parameters controlling crystallization, J. Am. Chem. Soc. 129 (2007) 13604-13612.

[12] P. Fleury, R. Köhlmuller, Mineral chemistry-on the system $\mathrm{Ag}_{2} \mathrm{O}-\mathrm{V}_{2} \mathrm{O}_{5}, \mathrm{C}$. R. Acad. Sci. 262 (1966) 475-477.

[13] S. Kittaka, K. Matsuno, H. Akashi, Crystal structure of $a-\mathrm{AgVO}_{3}$ and phase relation of $\mathrm{AgVO}_{3}$, J. Solid State Chem. 142 (1999) 360-367.

[14] P. Fleury, Études sur les systemes $\mathrm{V}_{2} \mathrm{O}_{5}-\mathrm{CuO}$ ou $\mathrm{Ag}_{2} \mathrm{O}$ ou $\mathrm{Tl}_{2} \mathrm{O}_{3}$ et sur les combinasions interoxydes correspondantes, Rev. Chim. Miner. 6 (1969) 819851.

[15] X. Hu, C. Hu, J. Qu, Preparation and visible-light activity of silver vanadate for the degradation of pollutants, Mater. Res. Bull. 43 (2008) 2986-2997.

[16] R.D. Holtz, A.G. Souza-Filho, M. Brocchi, D. Martins, N. Durán, O.L. Alves, Development of nanostructured silver vanadates decorated with silver nanoparticles as a novel antibacterial agent, Nanotechnology 21 (2010) 185102-185110.

[17] Z. Ji, M.N. Ismail, D.M. Callahan, E. Pandowo, Z. Cai, T.L. Goodrich, K.S. Ziemer, J. Warzywoda, A. Sacco, The role of silver nanoparticles on silver modified titanosilicate in visible light photocatalysis, Appl. Catal. B. Environ. 102 (2011) 323-333.

[18] R. Konta, H. Kato, H. Kobayashi, A. Kudo, Photophysical properties and photocatalytic activities under visible light irradiation of silver vanadates, Phys. Chem. Chem. Phys. 5 (2003) 3061-3065.

[19] S. Zhang, W. Li, C. Li, J. Chen, Synthesis, characterization, and electrochemical properties of $\mathrm{Ag}_{2} \mathrm{~V}_{4} \mathrm{O}_{11}$ and $\mathrm{AgVO}_{3}$ 1-D nano/microstructures, J. Phys. Chem. B 110 (2006) 24855-24863.

[20] G.B. Hoflund, Z.F. Hazos, G.N. Salaita, Surface characterization study of Ag, AgO, and $\mathrm{Ag}_{2} \mathrm{O}$ using $\mathrm{X}$-ray photoelectron spectroscopy and electron energy-loss spectroscopy, Phys. Rev. B 62 (2000) 11126-11133.

[21] N. Serpone, Relative photonic efficiencies and quantum yields in heterogeneous photocatalysis, J. Photochem. Photobiol. A 104 (1997) 1-12.

[22] P. Qu, J. Zhao, T. Shen, H. Hidaka, $\mathrm{TiO}_{2}$-assisted photodegradation of dyes: a study of two competitive primary processes in the degradation of $\mathrm{RB}$ in an aqueous $\mathrm{TiO}_{2}$ colloidal solution, J. Mol. Catal. A - Chem. 129 (1998) 257-268.

[23] R. Masse, M.T. Averbuch-Pouchot, A. Durif, J.C. Guitel, Chemical preparation and crystal structure of silver pyrovanadate, $\mathrm{Ag}_{4} \mathrm{~V}_{2} \mathrm{O}_{7}$, Acta Cryst. C 39 (1983) 1608-1610.

[24] X. Wang, S. Li, H. Yu, J. Yu, S. Liu, $\mathrm{Ag}_{2} \mathrm{O}$ as a new visible-light photocatalyst selfstability and high photocatalytic activity, Chem. A Eur. J. 17 (2011) 7777-7780. 